\title{
Ultrastructural Changes in The Cell Wall Of Erv14 Mutants From The Yeast Saccharomyces cerevisiae
}

\author{
Mario Velasco-Ramos ${ }^{1}$, Daniel Lagunas-Gómez ${ }^{2}$, Omar Pantoja ${ }^{2}$ and Guadalupe Zavala ${ }^{3 *}$ \\ 1. Facultad de Ciencias, Laboratorio de Microscopia Electrónica, UNAM, Ciudad Universitaria, \\ Ciudad de México, México. \\ 2. Departamento de Biología Molecular de Plantas, IBT, UNAM, Cuernavaca, Morelos, México. \\ 3. Unidad de Microscopia Electrónica, IBT, UNAM, Cuernavaca, Morelos, México. \\ * Corresponding author: gzavala@ibt.unam.mx
}

Yeast cells are particularly impermeable to exogenous agents mainly due to the presence of the cell wall. New techniques like cryofixation do not help much in improving the intracellular ultrastructure of $S$. cerevisiae under TEM.

We were able to observe structural changes in the cell wall from wild type (wt) and S134D, S134A, ${ }^{134} \mathrm{DAAA}^{137}$ and ${ }^{134} \mathrm{AAAA}^{137}$ Erv14 mutant yeast cells by employing chemical fixation and standard procedures, with $\mathrm{KMnO}_{4}$ or $\mathrm{OsO}_{4}$ treatments under TEM at $80 \mathrm{kV}$.

In cells stained with $\mathrm{KMnO} 4$ before embedding the wall showed layers with distinct structure (fig.1) but the yeast walls appeared transparent to the electrons in uranyl acetate stained sections in samples previously treated with $\mathrm{KMnO} 4$ (fig. 2).

The strain characteristics may be an explanation for the structural differences of the cell wall in mutant yeasts. 


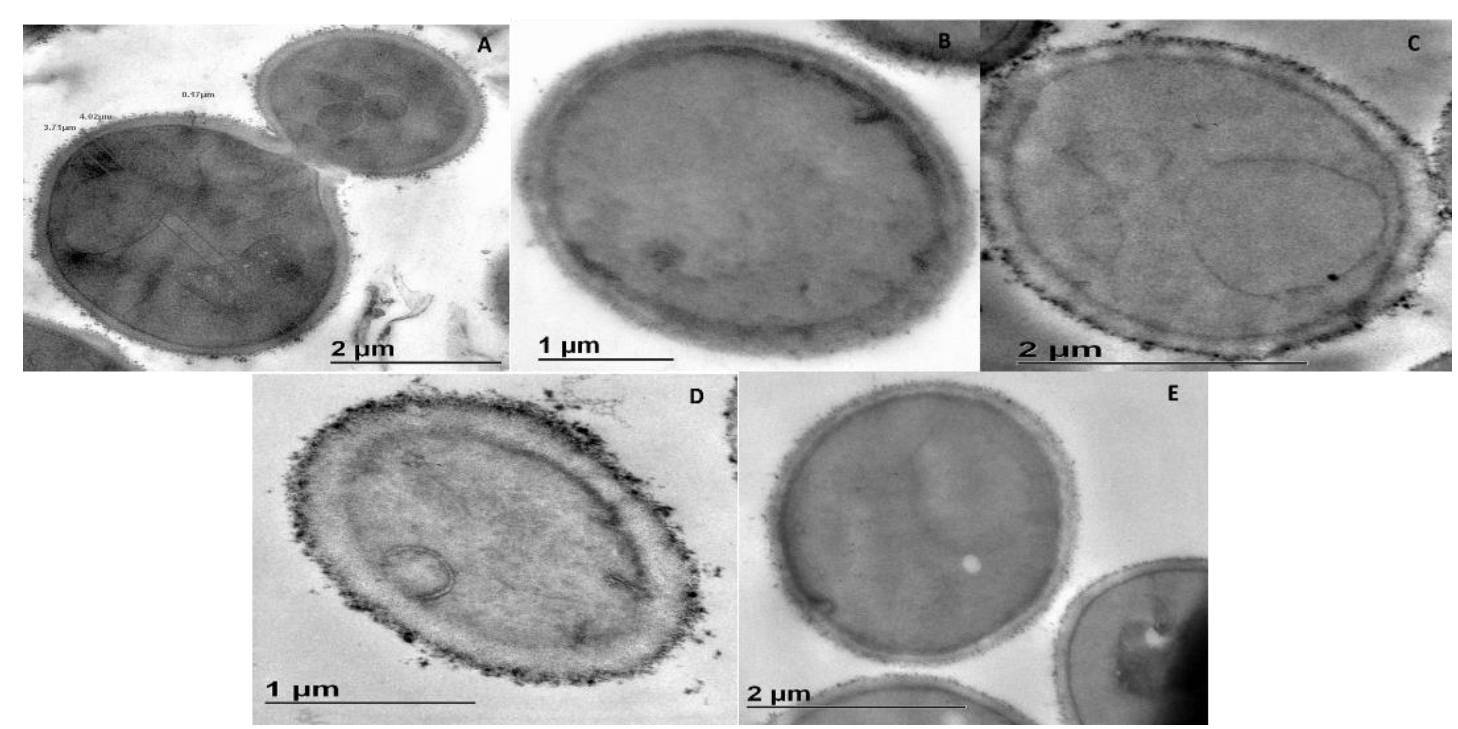

Figure 1. Electron micrograph of $S$. cerevisiae in sections of wild type and mutant cells stained with KMnO4. Notice the different structure of the cell wall in each case: Wt A), SD mutant B), SA mutant C), DAAA mutant D) and AAAA mutant E). Images taken at 6,000 X magnification.

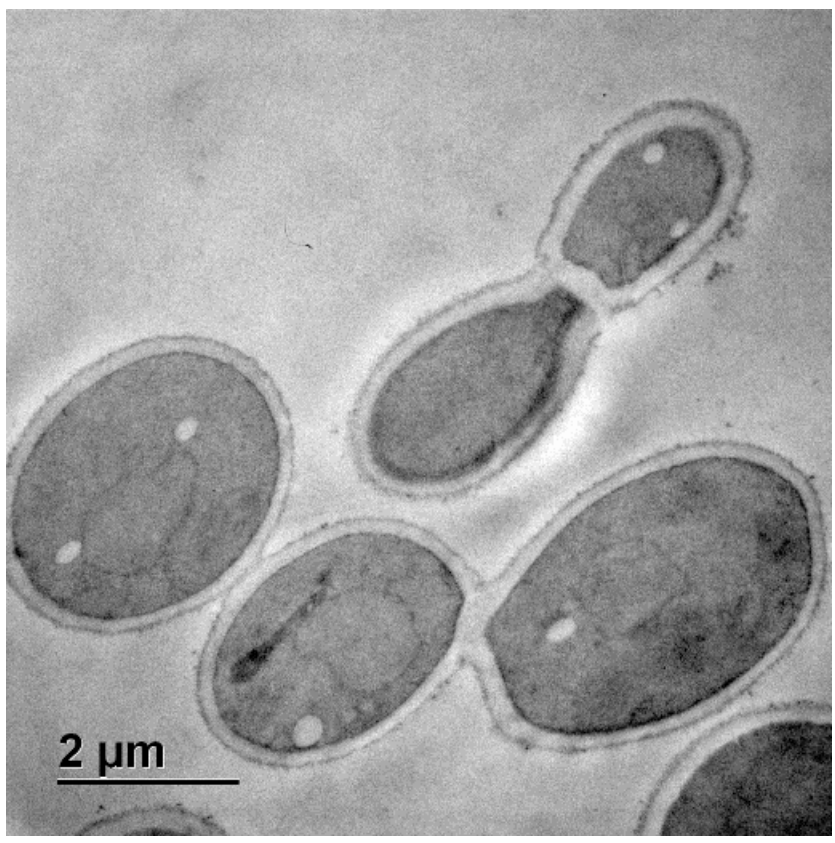

Figure 2. Electron micrograph showing cell ultrastructure from $S$. cerevisiae wild type cells post-fixed with $\mathrm{KMnO}_{4}$ and uranyl acetate and Reynold's lead citrate stain. Image taken at 4,000 X magnification.

\section{References:}

[1]. J. Herrera-Ruiz et al., Fungal Genet. Biol. 20 (1996), p. 133.

[2]. R. Wright, Microscopy Research and Technique. 51 (2000), p. 496.

[3]. C. Bauer, et al., Microsc. Microanal. 7 (2001), p. 539.

[4]. M. Osumi, Journal of Electron Microscopy. 61 (2012), p. 343.

[5]. A. Frankl, et al., Microbial Cell. 2 (2015), p. 412. 